\title{
Should euro area countries cut taxes on labour or capital in order to boost their growth? ${ }^{\text {is }}$
}

\section{Barbara Castelletti Font, Pierrick Clerc *, Matthieu Lemoine}

Banque de France, France

\section{A R T I C L E I N F O}

\section{JEL classification:}

E62

E63

F42

Keywords:

Fiscal reforms

Taxes

Government spending

DSGE model

\begin{abstract}
A B S T R A C T
The large imbalances within the euro area have led to a renewed interest in tax policies that could reduce labour costs and thus improve competitiveness and growth. In this paper, we consider whether it would be more growth-enhancing for euro area countries to, instead, use capital income tax cuts. To address this issue, we focus on the open-economy dimension and make simplifying assumptions concerning the completeness of insurance markets. Using a DSGE model calibrated for France within the euro area, we show that the increase in output resulting from tax cuts on capital income would indeed be higher than the increase in output resulting from tax cuts on labour, both in the short and long run. Importantly, the strong response of output to capital income tax cuts appears to be partly explained by the particularly high level of capital income taxes in France. Moreover, such tax cuts would be less efficient if they were expected to be only temporary. Finally, we illustrate our main points through a recent fiscal package implemented in France, which combines labour and capital income tax cuts. After briefly assessing this package, we find that investment and real output would have been more strongly boosted in the medium run if this package had been focused to a larger extent on reductions in capital income taxes.
\end{abstract}

\section{Introduction}

Since the launch of the euro, internal imbalances have been a strong feature of the euro area. In the absence of exchange rate adjustments, some international institutions have recommended cutting labour taxes (notably through a shift towards the consumption tax) in order to improve competitiveness, employment and growth in countries suffering from current account deficits (e.g. IMF, 2014; European Commission, 2013). In practice, some governments implemented such tax reforms, e.g. Germany in 2006, while others have simultaneously reduced taxes on labour and on capital income, e.g. France in 2013. So far, the debate about the design of tax reforms has mainly focused on the effect of labour tax cuts and on the degree to which they target low wages. $^{1}$
In this paper, we consider whether it would be more growthenhancing for euro area countries to use capital income cuts rather than labour tax cuts. More precisely, we consider two alternative schemes for tax alleviation: cutting on capital income tax, for both corporate income and capital owned by households; and reducing employers' social contributions, with a more direct impact on labour costs. In contrast with the literature pioneered by Chamley (1986) and Judd (1985) on capital income optimal taxation, we adopt a positive approach: we try to assess what DSGE models with usual frictions can tell us about the impact of such taxes on key macroeconomic variables, instead of looking at their optimal level with respect to welfare. We focus on the open-economy dimension and leave for further research the analysis of such effects for

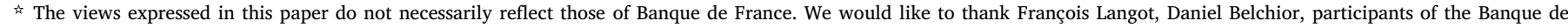
France seminar and those of the T2M 2017 conference for useful comments and suggestions.

* Corresponding author.

E-mail addresses: Barbara.CastellettiFont@banque-france.fr (B.C. Font), Pierrick.Clerc@live.fr, Pierrick.Clerc@banque-france.fr (P. Clerc), Matthieu.Lemoine@banque-france.fr (M. Lemoine).

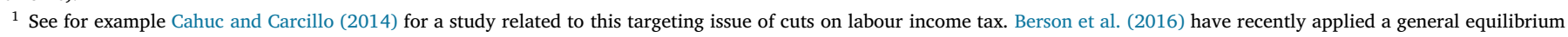

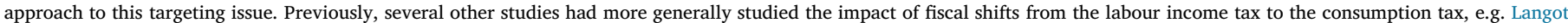

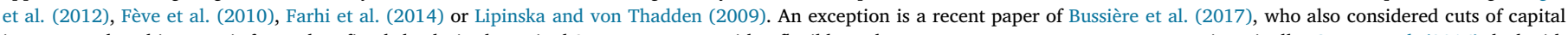

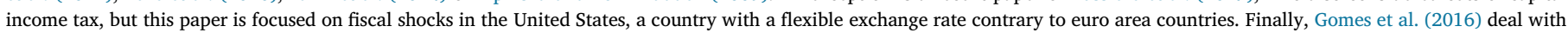
fiscal devaluation in the euro area within EAGLE, a DSGE model close to ours.
} 

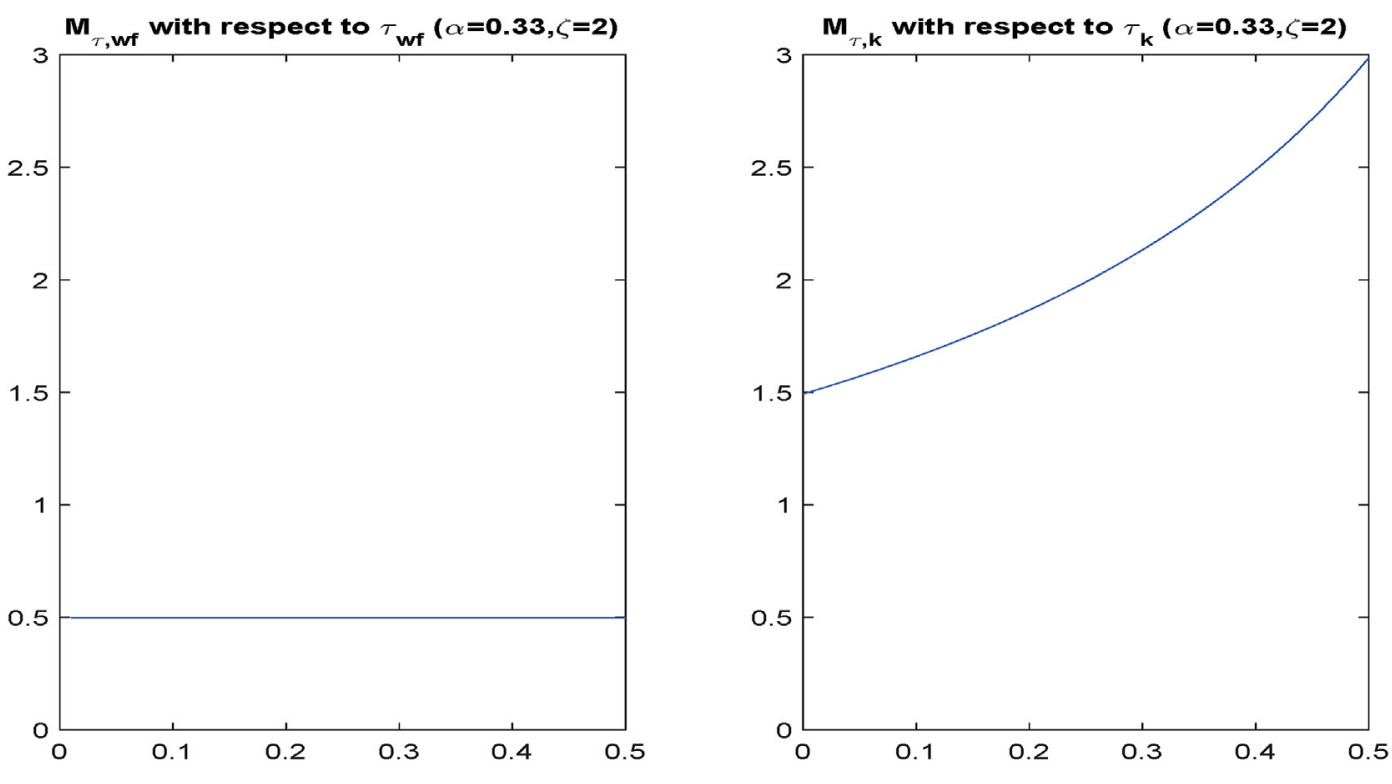

Fig. 1. Capital and labour tax multipliers as a function of tax-rate levels.

incomplete insurance-market economies. ${ }^{2}$

The contribution of this paper is twofold. In a first stage, we provide simple intuitions about the different impact of these two instruments on economic growth by using a simple Real Business Cycle (RBC) model. Indeed, we demonstrate the stronger long-run effect on output for permanent reductions in capital income taxes. Moreover, this effect is non-linear: the size of this effect increases with the level of capital income tax from which the cut is implemented. Second, we refine this quantitative analysis by building a larger DSGE model with more realistic features ${ }^{3}$ and calibrated for France within the euro area. France is chosen as an example of a euro area country with current account deficits that recently experienced labour and capital income tax alleviation. Against this backdrop, we show that permanent shocks on capital income taxes have a stronger impact on output both in the short and long run. This conclusion is reinforced for France, given the high level of capital income taxation compared to the rest of the euro area. Still, reductions in capital income taxes would be less efficient if they are only temporary, or alternatively if their implementation is perceived as imperfectly credible.

We also illustrate these points by taking into account a package of fiscal reforms implemented in France since 2013: the Credit d'Impôt pour la Compétitivité et l'Emploi (CICE), which was subsequently incorporated into a broader Responsibility and Solidarity Pact ("Pacte de Responsabilité et Solidarité" - PRS) in January 2015. Roughly speaking, these reforms involve reductions in labour and capital income taxes, financed by tax hikes on consumption and decreases in government spending. We first provide an assessment of this package as it was implemented. Then we show that it would have raised investment and output by a larger amount if the tax cuts had been more focused on capital income. With such an alternative package, employment would have fallen somewhat in the short run (due to a degree of substitution in capital for labour) but would

\footnotetext{
${ }^{2}$ It is worth mentioning, however, that we retain two features which limit the completeness of insurance markets: non-Ricardian households and imperfect substitution of internationally exchanged bonds. In a closed-economy framework, the role of incomplete markets for tax multipliers has been studied in Heathcote (2005).

${ }^{3}$ These features include the open economy dimension of euro area countries, the role of monetary policy, the calibration of a detailed fiscal block, the presence of non-Ricardian households and the usual set of real/nominal frictions.
}

have risen more in the medium run given the higher increase in output.

The DSGE model we build to address these issues, called the FRance in Euro Area Model (FREAM), has the following features. First, its core is similar to that of Smets and Wouters (2003), which incorporates the main frictions necessary for obtaining realistic impulse responses. Second, the French economy is modeled as an open-economy which trades with the rest of the euro area (REA) and an exogenous rest of the world, so as to take account of the effect of competitiveness gains. Third, the reduced weight of France within the monetary policy matters for the real interest rate reaction and its impact on investment dynamics. Fourth, we distinguish between public investment and public consumption to account for a potential negative impact of governments' investment cuts on the supply side of the economy.

This model is close to NAWM, a 2-country model of the euro area and the United States, developed at the ECB by Coenen et al. (2008). However, it allows to distinguish France within the euro area. In this sense, it is very similar to EAGLE (Euro Area and GLobal Economy), ${ }^{4}$ which also builds on NAWM. FREAM is nevertheless simpler than EAGLE in two ways. First, EAGLE consists of four endogenous blocks (Germany, the rest of the euro area, the US and the rest of the world) instead of two endogenous ones (France, the rest of the euro area) and an exogenous rest of the world for FREAM. Secondly, EAGLE features tradable and non-tradable intermediate goods instead of only tradable intermediate goods in the case of FREAM. This lightened structure for FREAM makes it easier to understand the effects resulting from the interactions between regions.

This paper is structured as follows. After providing simple intuitions about the long-run impact of capital and labour taxes in a simple RBC model (Section 2), we will briefly present a more detailed DSGE framework for studying the effect of such taxes in euro area countries (Section 3). Then, we present the simulations results obtained with this model for standard shocks (Section 4). Finally, we apply our framework to the analysis of fiscal reforms implemented in France since 2013 (Section 5) and we then conclude (Section 6).

\footnotetext{
${ }^{4}$ See Gomes et al. (2012) for a presentation of EAGLE.
} 

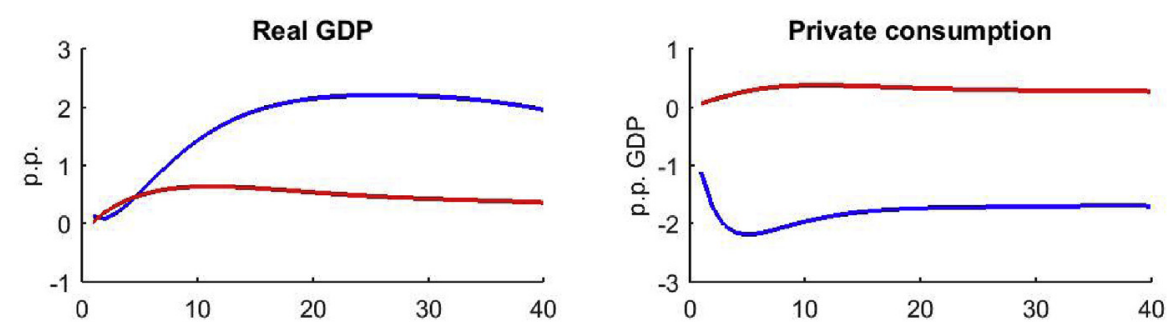

Fig. 2. Permanent reduction of $1 \%$ of GDP in capital taxes and SSC (France, deviation from steady state).
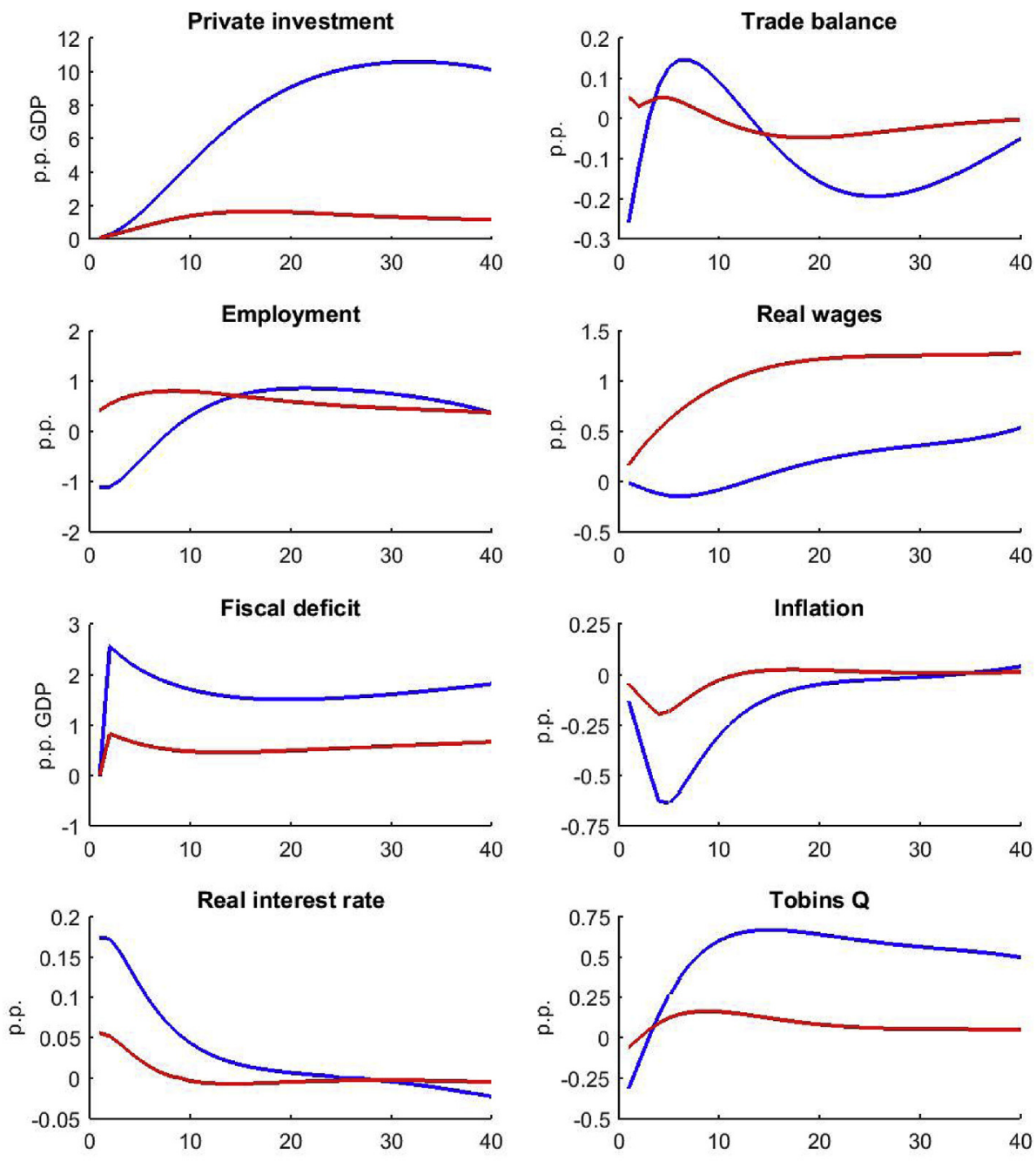

Shock $\tau_{\mathrm{k}} \longrightarrow$ Shock $\tau_{\mathrm{Wf}}$

\section{Some first insights from the steady state of a RBC model}

Before turning to a richer DSGE framework it is useful to illustrate two of the main points of this paper within a simple RBC model. These points are: 1) variations in the taxation of capital incomes have a higher impact on output than those in the taxation of labour for firms; 2) the existence of non-linearities in the taxation of capital. More precisely, we consider the steady-state of a model whose basic components are a utility function $u(c, n)=$ $\frac{c^{1-\sigma}}{1-\sigma}-\frac{n^{1+\zeta}}{1+\zeta}$, a Cobb-Douglas production function, a nil depreciation and three taxes. For simplifying the following conditions, we assume $\sigma=1$. The resulting first-order and market-clearing conditions are:
- Euler condition: $1 / \beta=\left(1-\tau^{K}\right) \alpha k^{\alpha-1} n^{1-\alpha}+1$

- Labour-market equilibrium: $n^{\zeta} c=\frac{(1-\alpha) k^{\alpha} n^{-\alpha}}{1+\tau^{W_{f}}}$

- Clearing condition \& production function: $c=y=(k / n)^{\alpha} n$

- Budget constraint of govt: $0=\tau^{k} \alpha k^{\alpha} n^{1-\alpha}+\tau^{W_{f}} \frac{(1-\alpha) k^{\alpha} n^{1-\alpha}}{1+\tau_{w f}}+T$

with $c$ aggregate consumption, $n$ total employment, $\zeta$ the inverse of the Frisch elasticity of labour-supply, $\beta$ the discount factor, $\tau^{K}$ the tax on capital income, $\alpha$ the elasticity of production with respect to capital, $k$ the stock of capital, $\tau^{W_{f}}$ the tax on labour paid by employers, $y$ aggregate output and $T$ lump-sum taxes.

Aggregate output can be related both to $\tau_{k}$ (through capital intensity) and to $\tau^{W_{f}}$ (through labour). This implies: 

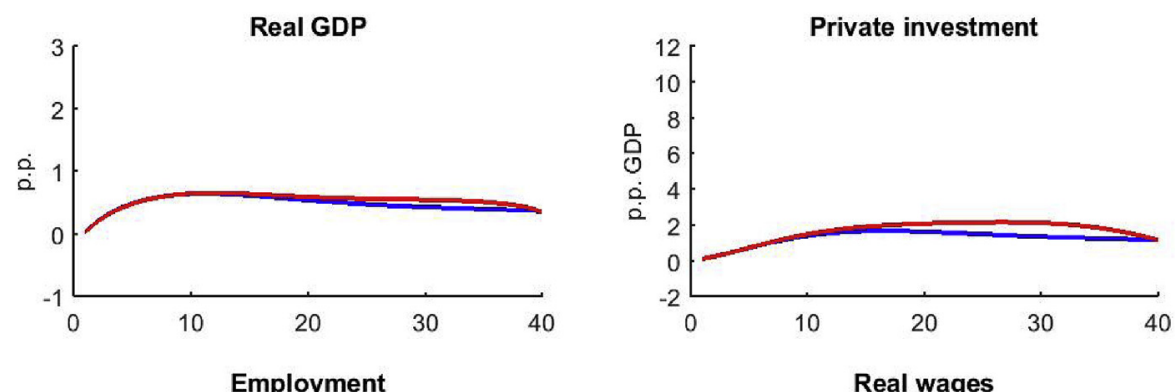

Fig. 3. Permanent and transitory reductions in $\tau^{W_{f}}$ of $1 \%$ of GDP (France, deviation from steady state).
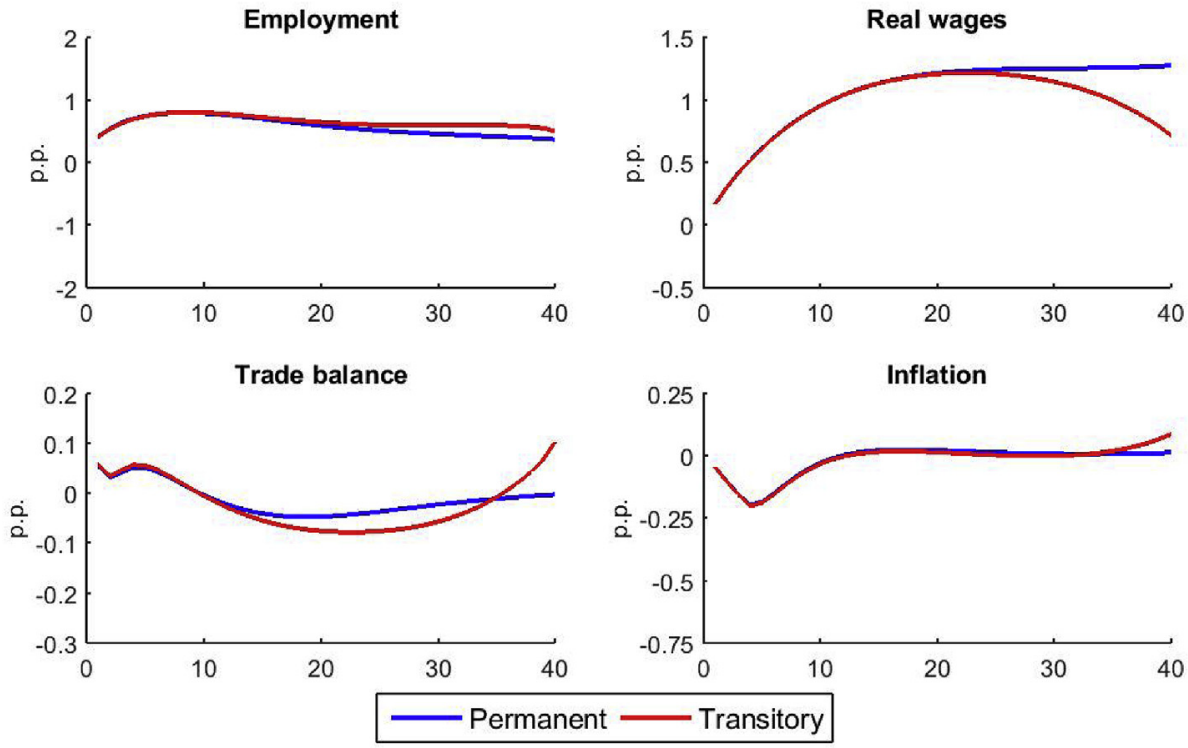

$y=\varphi^{\alpha}\left(1-\tau^{K}\right)^{\frac{\alpha}{1-\alpha}} \mu\left(1+\tau^{W_{f}}\right)^{-\frac{1}{\zeta+1}}$

with $\varphi=\left(\frac{\alpha}{1 / \beta-1}\right)^{\frac{1}{1-\alpha}}$ and $\mu=(1-\alpha)^{\frac{1}{\zeta+1}}$.

The long-run output multipliers to shocks (of -1pp of output) on $\tau^{W_{f}}$ and $\tau^{K}$ are, respectively:

$$
\begin{aligned}
& -M_{\tau} W_{f}=-\frac{1+\tau^{W_{f}}}{1-\alpha} \frac{d \log y}{d \tau^{W_{f}}}=\frac{1}{(1-\alpha)(\zeta+1)} \\
& \text { - } M_{\tau^{K}}=-\frac{1}{\alpha} \frac{d \log y}{d \tau^{K}}=\frac{1}{1-\alpha} \frac{1}{1-\tau^{K}}
\end{aligned}
$$

The first difference between these two multipliers is that the multiplier related to $\tau^{K}$ is always larger than that related to $\tau^{W_{f}}$. On the one hand, the Frisch elasticity of labour supply $1 / \zeta$ is crucial for the multiplier of $\tau^{W_{f}}$ : the larger this elasticity, the larger the multiplier; with an infinite elasticity, we obtain the same multiplier as that of $\tau^{K}$. On the other hand, even if we had not set the inter-temporal elasticity of substitution $\sigma$ at 1 , this parameter would not matter for the equilibrium of the capital market (Euler condition) ${ }^{5}$ : since we are at the steady-state, the ratio of marginal utilities of consumption is always equal to 1 . Hence, this elasticity does not influence the response of capital intensity to shocks on $\tau^{K}$.

The second difference between these two multipliers is that the multiplier related to $\tau^{K}$ does depend on the actual rate of capital taxation, whereas the multiplier related to $\tau^{W_{f}}$ does not depend on the actual rate of labour taxation for employers. Moreover, the multiplier related to $\tau^{K}$ is a positive function of the actual rate

${ }^{5}$ If we had not set at 1 this inter-temporal elasticity of substitution, it would still appear in the equation of the labour-market equilibrium, but it would not qualitatively change our two results at least for reasonable values (between 1 and 2). of capital taxation. Hence, the higher the level of capital taxation, the larger the increase in output resulting from a reduction in $\tau^{K}$. Fig. 1 gives a numerical illustration for standard values of $\alpha$ and $\zeta$.

The left panel of Fig. 1 delivers the long-run multipliers of a decrease (representing 1pp of output) of $\tau^{W_{f}}$. These multipliers are equal to 0.5 , irrespective of the level of $\tau^{W_{f}}$ from which the decrease is implemented. The right panel of Fig. 1 provides the long-run multipliers of a reduction (still representing 1pp of output) of $\tau^{K}$. In this case, whatever the level of taxation, the multipliers are higher than those of reductions in $\tau^{W_{f}}$. Moreover, these multipliers are increasing (in absolute value) in the level of $\tau^{K}$ from which the reduction is implemented. For instance, the multiplier is equal to 1.7 when the initial level of $\tau^{K}$ is $10 \%$, whereas it amounts to 3 for an initial level of $\tau^{K}$ at $50 \%$. An interesting comparison, which we will consider in more depth below, lies between the value of the multiplier of $\tau^{K}$ for France and for the Rest of the Euro Area (REA). In France, $\tau^{K}$ is around 36\%. This implies a long-run multiplier of $\tau^{K}$ equal to 2.35. In the REA, $\tau^{K}$ amounts to $27 \%$ on average. This entails a long-run multiplier of $\tau^{K}$ equal to 2 .

\section{FREAM: a multi-country DGSE approach to fiscal policy}

This section presents the main features lying at the core of FREAM, a model for the French economy in the context of the euro area. We particularly highlight those aspects with a meaningful role for fiscal policy, on which our analysis focuses. Given that FREAM largely builds on the version of NAWM developed by Coenen et al. (2008), the full model and its derivation are detailed in the Appendix of the working paper of this article. ${ }^{6}$

${ }^{6}$ Castelletti et al. (2017). 

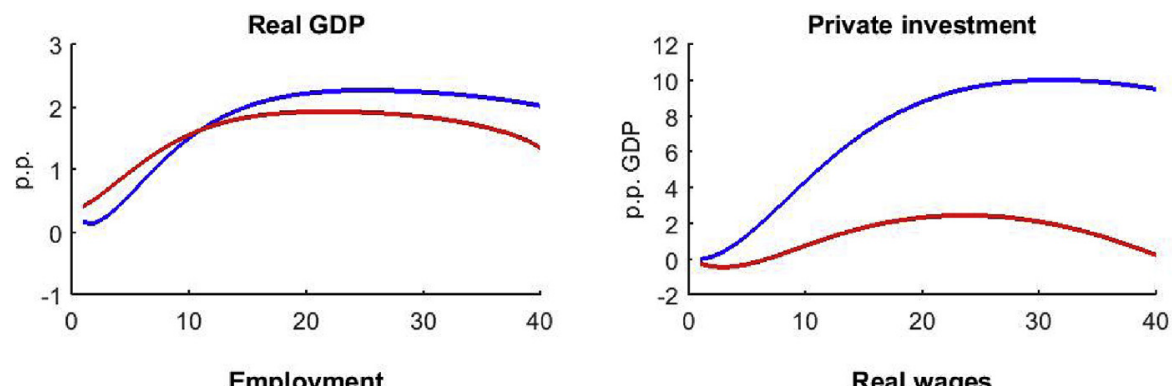

Fig. 4. Permanent and transitory reductions in $\tau^{K}$ of $1 \%$ of GDP (France, deviation from steady state).
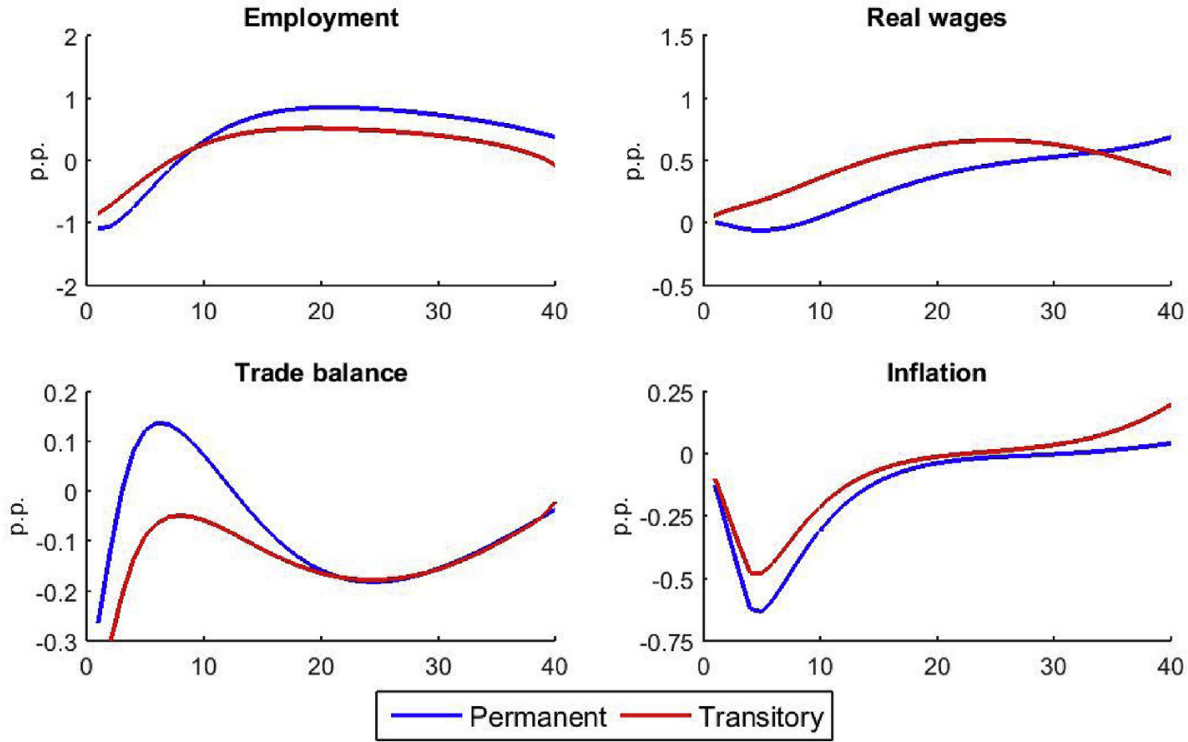

\subsection{Brief description of FREAM}

FREAM is a multi-country DSGE comprising two symmetric regions, France and the REA, trading both goods and government bonds between them and with an exogenous rest of the world (RoW, indexed with an asterisk *). In each region, there are four types of economic agents: households, firms, a fiscal authority and a monetary authority.
Households are shared between Ricardian households, who have access to financial markets and own capital, and Non-Ricardian ones who can only hold money and consume their current income in each period. There are two subsets of firms: producers of tradable differentiated intermediate goods who operate on monopolistically competitive markets with sticky prices, and producers of non-tradable goods who trade these goods on competitive markets with flexible prices. The gov-
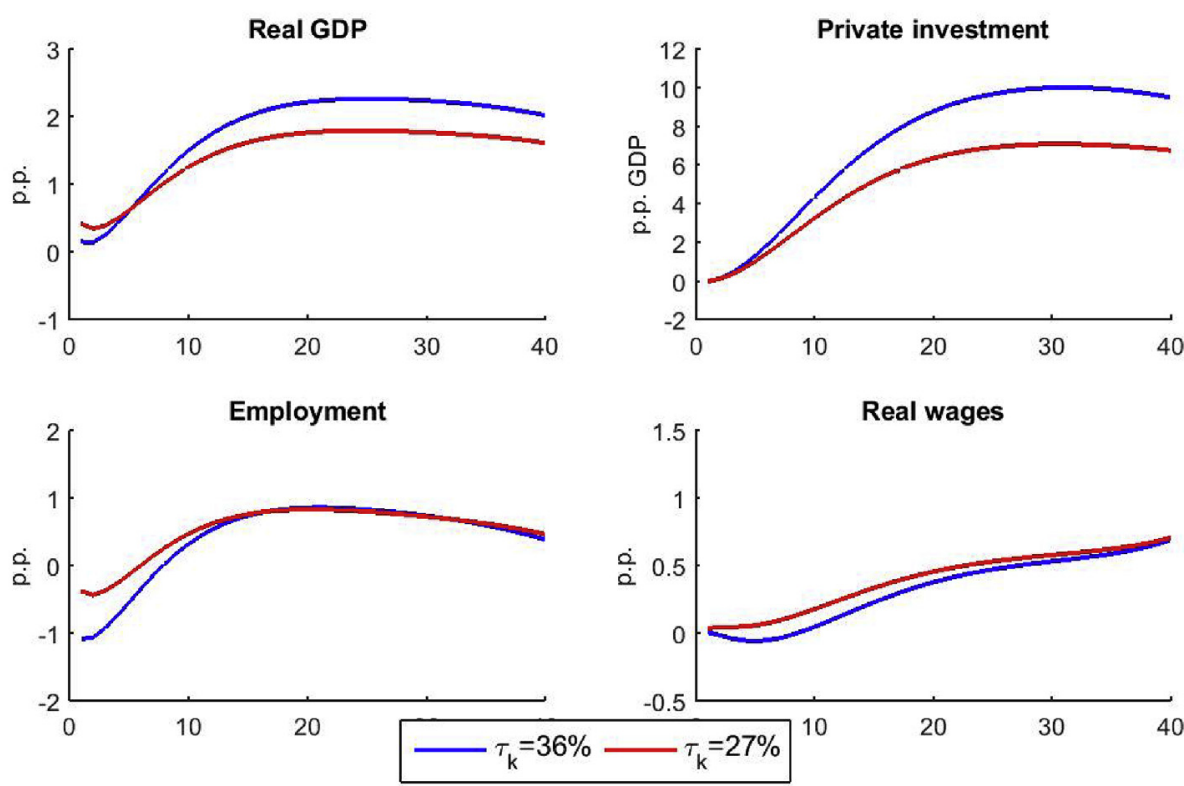

Fig. 5. Permanent reduction of $1 \%$ of GDP for different initial values of $\tau^{K}$ (France, deviation from steady state). 
Table 1

\begin{tabular}{llllll}
\hline CICE-PRS measures (cumulated EUR billion). & & & \\
\hline \multirow{2}{*}{ Expansionary measures } & & 2014 & 2015 & 2016 & 2017 \\
& SSC employers $\left(\tau_{t}^{W_{f}}\right)$ & 0.0 & -5.5 & -8.6 & -9.6 \\
& SSC households $\left(\tau_{t}^{W_{h}}\right)$ & -1.3 & -2.9 & -4.9 & -4.9 \\
& Corporate income tax $\left(\tau_{t}^{K}\right)$ & 0.0 & -1.0 & -4.0 & -9.5 \\
& CICE tax credit $\left(\tau_{t}^{W_{f}}, \tau_{t}^{K}\right)$ & -10.2 & -17.3 & -18.5 & -19.3 \\
Recessionary measures & VAT and ecological taxes $\left(\tau_{t}^{C}\right)$ & 6.2 & 9.9 & 12.7 & 13.8 \\
& Gov. consumption $\left(G_{t}\right)$ & -3.0 & -9.5 & -13.7 & -18.2 \\
& Transfers $\left(T R_{t}\right)$ & -1.3 & -4.0 & -3.2 & -3.3 \\
& Public investment $\left(I_{G, t}\right)$ & -1.1 & -3.4 & -6.4 & -8.1 \\
\hline
\end{tabular}

a In the "baseline" scenario, the CICE tax credit is assigned in equal shares (50\%) to $\tau_{t}^{W_{f}}$ and $\tau_{t}^{K}$. In the "alternative" case we assume that the whole amount of the CICE (100\%) is assigned to $\tau_{t}^{K}$.

Source: Banque de France calculations.

ernment raises taxes and provides public spending with a fiscal policy rule ensuring long-run sustainability. The central bank sets the nominal interest rate for the euro area as a whole (France and REA are in a monetary union and share the same monetary policy), following a standard Taylor-type rule. ${ }^{7}$

\subsection{Inclusion of fiscal shocks in the model}

In order to better capture the effects on the economy of the different public spending instruments, we split the public demand into public consumption $\left(G_{t}\right)$ and investment $\left(I_{G, t}\right)$. The main difference between these two components lies in the assumption that public investment is productive and, therefore, enhances the production function of private firms. In contrast, public consumption affects aggregate demand without impacting on the private sector.

The budget constraint of the fiscal authority will, therefore, reflects the purchases of the two aforementioned public goods. In addition, the government makes social transfers $\left(T R_{t}\right)$, issues bonds to refinance its debt $\left(R_{t}^{-1} B_{t+1}-B_{t}\right)$ and earns seigniorage on money holdings $\left(M_{t}-M_{t-1}\right)$. In order to finance public spending, the government raises taxes on consumption $\left(\tau_{t}^{C}\right)$, incomes stemming from capital $\left(\tau_{t}^{K}\right)$ and labour $\left(\tau_{t}^{N}\right)$ and social security contributions from employers $\left(\tau_{t}^{W_{f}}\right)$ and workers $\left(\tau_{t}^{W_{h}}\right)$. In what follows, we will focus on shocks on $\tau_{t}^{K}$ and $\tau_{t}^{W_{f}}$. The period-by-period budget constraint then has the following form:

$$
\begin{aligned}
P_{G, t} G_{t} & +P_{I_{G}, t} I_{G, t}+T R_{t}+B_{t}+M_{t-1} \\
= & \tau_{t}^{C} P_{C, t} C_{t}+\left(\tau_{t}^{N}+\tau_{t}^{W_{h}}\right)\left(\int_{0}^{1-\omega} W_{i, t} N_{i, t} d i+\int_{1-\omega}^{1} W_{j, t} N_{j, t} d j\right) \\
& +\tau_{t}^{W_{f}} W_{t} N_{t}+\tau_{t}^{K}\left(R_{K, t} u_{t}-\left(\Gamma_{u}\left(u_{t}\right)+\delta\right) P_{I, t}\right) K_{t} \\
& +\tau_{t}^{D} D_{t}+T_{t}+R_{t}^{-1} B_{t+1}+M_{t}
\end{aligned}
$$

A fiscal rule is assumed to stabilise the government debt-to-output ratio towards the desired target $B_{Y}$ as depicted in the following equation.

$$
\tau_{t}^{N}=\phi_{B_{Y}}\left(\frac{B_{t}}{P_{Y} Y}-B_{Y}\right)
$$

We set the tax rate on labour income $\left(\tau^{N}\right)$ as the instrument that allows the debt ratio to stabilise in the long run at its target value. Furthermore, we assume that labour income taxes react to the change in the debt ratio with a 10-year lag, so as to isolate the short-run responses to shocks on budgetary variables from the fiscal rule in short and medium run. In order to ensure comparability across the figures, the size of standard shocks is set to 1 per cent of GDP. Since we are dealing with tax rates in our simulations, the shock is calculated in such a way that the

\footnotetext{
${ }^{7}$ This implies that the exchange rate is constant within the euro area.
}

initial change in the particular tax revenue is equal to a 1 per cent of the initial steady state GDP, thus considering the size of the tax base.

Our model is calibrated so as to reproduce the main macroeconomic aggregates observed in recent years for the three blocks of countries in FREAM. Because of the nature of our work, we devote special attention to the indicators that reproduce fiscal aggregates by compiling observed data. This strategy is presented in more detail in Section B of the Appendix.

\section{Simulation results for standard shocks}

In this section, we use FREAM to asses the effect on the economy for three standard scenarios involving capital and labour tax alleviation. We notably run simulations for shocks on $\tau_{t}^{K}$ and $\tau_{t}^{W_{f}}$ in three cases: 1) permanent shocks with the baseline calibration; 2) transitory shocks; 3) and a permanent shock on $\tau_{t}^{K}$ with a lower initial level in France.

\subsection{Permanent reduction of capital and labour taxes}

In this subsection we describe the main results of a permanent reduction of 1pp of GDP in $\tau_{t}^{K}$ and $\tau_{t}^{W_{f}}$. We contrast the potential benefits of each tax cut with a special focus on the dynamics of real output, employment and private investment. We analyse the impact of both policies over the medium term, i.e. for a time horizon of 4 years over which the measures are fully implemented. We also assess the impact of the measures over the long term, i.e. for a time horizon of 10 years over which the variables subject to adjustment costs have the time to converge.

Fig. 2 suggests that both scenarios significantly foster output growth, employment and private investment in the long run. Nonetheless, we also demonstrate that the way fiscal stimuli are implemented is crucial to determine the final outcome and the macroeconomic objective that is sought. Indeed, and in accordance with the results of Section 2, a permanent cut in taxes on capital income generates much larger positive long-run responses of output and private investment than a permanent cut in firms' social security contributions. ${ }^{8}$ A reduction in capital income taxes, however, is likely to be a less desirable choice in terms of labour in the short and medium run, especially for those households with no ability to participate in asset markets.

When analysing the impact of the capital income tax shock (blue lines in Fig. 2), a substantial rise in private investment is observed. Recall that due to the standard assumption of adjustment costs on the rate of growth of private investment, its level depends on the discounted

\footnotetext{
${ }^{8}$ Qualitatively, we would get similar results when implementing simultaneous shocks in France and in the rest of the euro area. The response of output and investment would also be larger for cuts of the capital income tax than for those of the tax on labour. This is also the case when we use different values for the parameters $\alpha_{G}$ and $\eta$. Results are available upon request.
} 

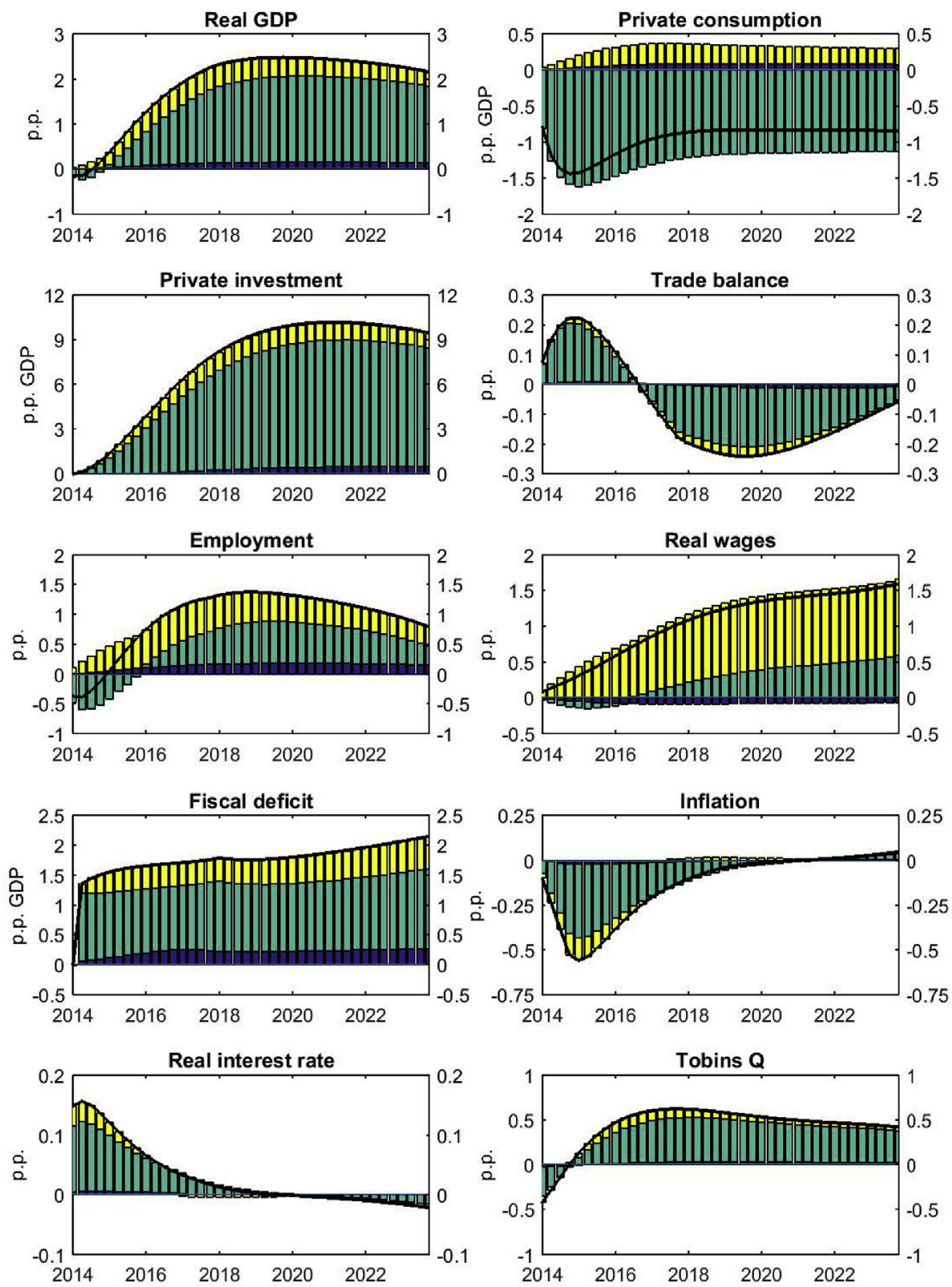

Fig. 6. Effect of the CICE-PRS "baseline" scenario, by shock contribution (France, deviation from steady state). sum of all expected future values of Tobin's Q. In the first periods, Tobin's $Q$ declines since there is a jump in the real interest rate. The rise in this rate results from the fall in inflation (tax reductions imply a decrease in firms' marginal costs) while the nominal interest rate is constant, given that it is determined at the euro area level as a whole. Subsequently, however, higher (after tax) returns on capital entail a large and persistent increase in Tobin's $Q$ which more than offsets its initial decline over private investment.

The substantial rise in private investment more than offsets the fall in private consumption, which implies an overall increase in real output. Private consumption decreases since the real interest rate jumps. At the same time, a decrease in $\tau^{K}$ makes capital more attractive and then generates a subsequent reallocation of production inputs from labour to capital. This produces a lower labour demand and thus a reduced level of employment in the short to medium run. In the long term, nevertheless, the fall in $\tau^{K}$, by significantly fostering real output, raises labour demand and employment. The behaviour of employment is reflected in the dynamics of the real wage, which initially declines (due to the fall in labour demand) before gradually increasing (due to the rise in labour demand).

Turning to the trade balance, the fall in $\tau^{K}$ implies a decrease in marginal costs and thus in export prices. French terms-of-trade therefore deteriorate, which creates an initial deficit of the trade balance. As time passes, the fall in export prices improves competitiveness, leading foreign countries to substitute French goods for their own domestic goods. Moreover, the terms-of-trade of these countries improve, entailing a positive wealth-effect which generates an increase in foreign aggregate demand and then in French exports. The competitiveness and wealth effects explain why the trade balance gradually displays a surplus. In the long run, however, the large increase in French aggregate demand (mainly due to private investment) turns into an increase in imports, which cancels out both the competitiveness and wealth effects 

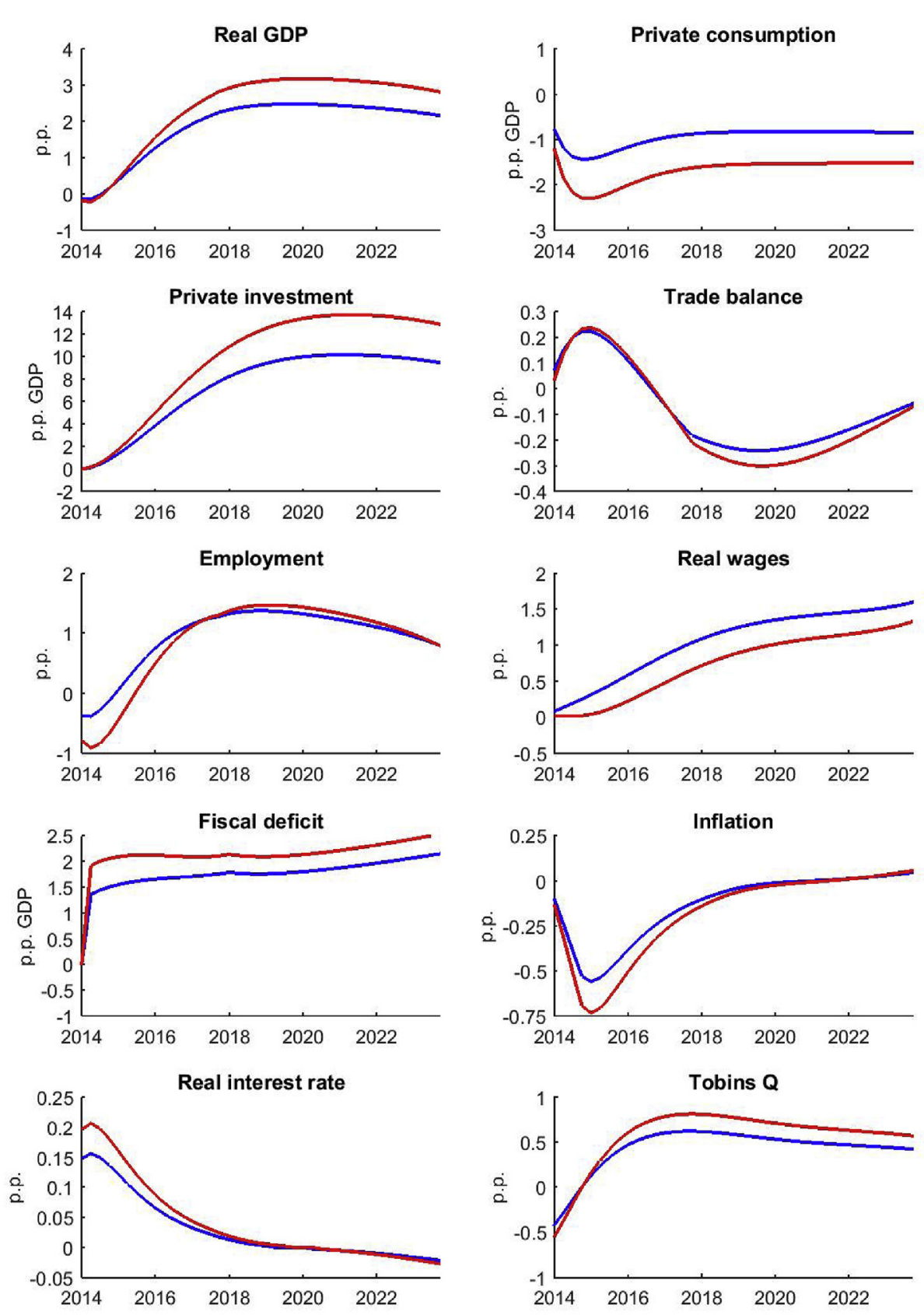
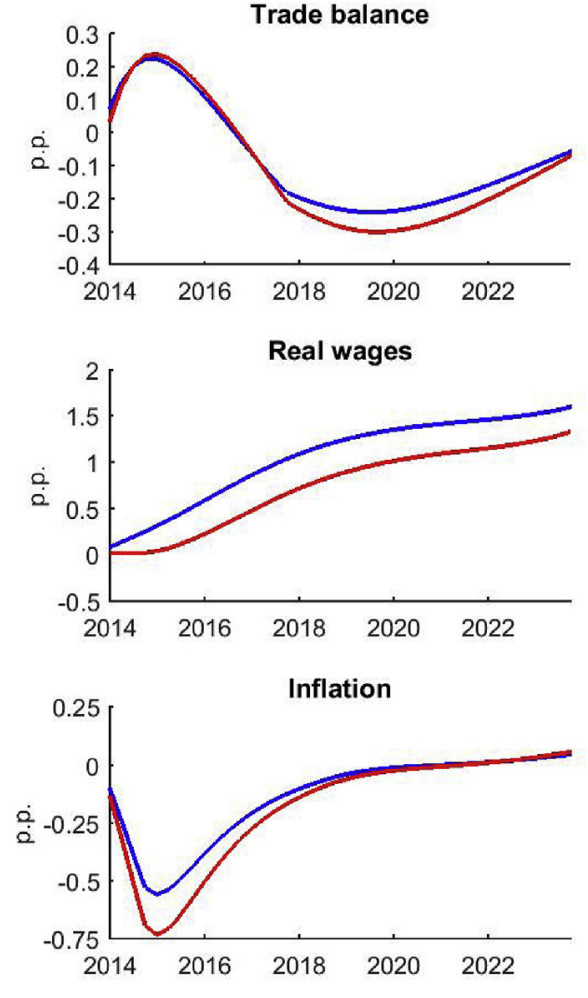

Tobins Q

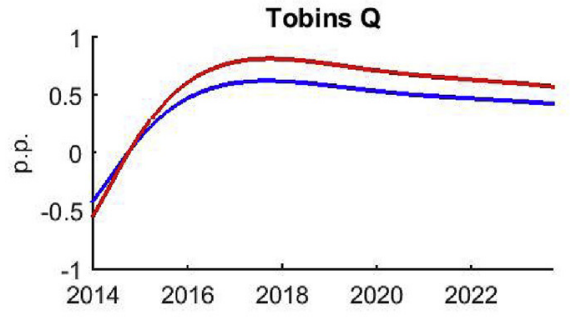

Fig. 7. Effect of the CICE-PRS ("baseline" and "alternative" scenarios) (France, deviation from steady state).

\section{Baseline — Alternative}

on the trade balance.

Consider now the shock on labour tax (red lines in Fig. 2). The decrease in $\tau^{W_{f}}$ generates an increase in labour demand which results in a persistent increase in both employment and real wages. This, in turn, enhances permanent income and therefore private consumption. This increase in private consumption (as well as in exports) somewhat raises expected returns on capital, Tobin's $Q$ and private investment. The rise in this latter variable is nevertheless much smaller than for a reduction in the capital income tax. Overall, and consistent with what we found in Section 2, the increase in real output is also much lower than in the case of a cut in $\tau^{K}$.
At the same time, the impact of a lower $\tau^{W_{f}}$ on firms' marginal costs is partly offset by the increase in real wages. Hence, inflation declines to a lower extent than for a reduction in $\tau^{K}$. The same reasoning applies to export prices, so that the deterioration in French terms-of-trade is less pronounced. On the other hand, the competitiveness and wealth effects are also lower than in the case of a shock on $\tau^{K}$. All this explains why the movements in the trade balance are less pronounced.

To sum up, a permanent reduction in $\tau^{K}$ is particularly well suited to foster private investment, real output and even employment in the long run. Alternatively, a permanent cut in $\tau^{W_{f}}$ seems the required policy to implement in order to raise employment (notably in the medium run), real wages and, to a lesser extent, private consumption. 


\subsection{Transitory reduction in capital and labour taxes}

In the last subsection, we focused our attention on permanent shocks on $\tau^{K}$ and $\tau^{W_{f}}$. We now consider transitory shocks on these taxes. Indeed, the red lines in Figs. 3 and 4 show the responses of reductions in $\tau^{K}$ and $\tau^{W_{f}}$, respectively (still amounting to 1pp of GDP), which last for 10 years. These taxes then revert back instantly to their initial values. For the sake of comparison, we reproduce (blue lines) the responses of permanent shocks computed in Fig. 2. It is worth noting that in the literature, transitory shocks are also meant to represent imperfect credibility of government in implementing tax cuts. Under this alternative interpretation, the government announces a permanent reduction in taxes (and effectively enforces it) but private agents believe that this tax cut will last only ten years.

Fig. 3 makes clear that the response of the main variables is quite independent from the duration of the cut in $\tau^{W_{f}}$. In other words, the impact of reductions in the taxation of labour for firms does not depend on the credibility of the government in implementing this tax cut.

On the other hand, Fig. 4 stresses that the duration of the shock in $\tau^{K}$, or the credibility of the government to enforce this tax cut permanently, is critical: the impact of the permanent tax reduction (full credibility) is much higher than the impact of the transitory tax reduction (imperfect credibility), most notably for investment and real output. This is probably related to the change in the steady state that occurs in the former case.

Indeed, the permanent reduction in $\tau^{K}$ is financed by an increase in $\tau^{N}$, through the fiscal rule. However, $\tau^{K}$ is more distortive than $\tau^{N}$, which implies a change in the steady state. Expectations of this change by private agents could lead them to amplify their response in the short run. This could explain the large difference with the transitory tax cut, for which the steady state is obviously unchanged. At the same time, the permanent reduction in $\tau^{W_{f}}$ is also financed by a rise in $\tau^{N}$. But $\tau^{W_{f}}$ and $\tau^{N}$ have the same degree of distortion, which leaves the steady state unchanged. Hence, the steady state remains the same for a permanent as well as for a transitory reduction in $\tau^{W_{f}}$. This could explain the relative similarity in the responses to reductions of different durations in this tax.

\subsection{Non-linearity in the taxation of capital: an assessment with FREAM}

We have shown in Section 2, within the steady-state representation of a simple RBC model, that the long-run multipliers of variations in the taxation of capital incomes depend on the taxation level from which these variations are implemented. This stands in sharp contrast with the taxation of labour for firms, for which the long-run multipliers are independent from the actual level of taxation. In order to provide a more precise picture of the non-linearities in capital taxation, notably in the short-run, we now illustrate the impact of variations in this taxation with FREAM.

Fig. 5 delivers the responses of real output, investment, employment and real wages to a permanent reduction in capital taxation (amounting to 1pp of GDP) for France. The blue line represents these responses for an initial capital tax rate of $36 \%$, which is the actual rate in France. The responses are the same as the ones we generated in Fig. 2. At the peak, private investment rises by $10 \%$, employment by $0.8 \%$ and real output by $2.3 \%$. The red line represents the responses if France had the same capital income taxation as in the REA, namely $27 \%$. In this counter-factual case, private investment would rise by $7 \%$, employment by $0.55 \%$ and real output by $1.7 \%$.

Consistent with the findings of Section 2, the impact of a reduction in $\tau^{K}$ is larger when this rate is high. The results of Fig. 5 therefore extend those of Section 2 in our richer model and we see that the non-linearity also matters in the short-run. Moreover, the stronger impact is particularly striking for private investment, since this variable is directly impacted by the variations in $\tau^{K}$.

\section{An application: the assessment of the CICE-Responsibility and Solidarity Pact}

In what follows, we consider the instruments involved in a recent fiscal package implemented in France: the Crédit d'Impôt pour la Compétitivité et l'Emploi (CICE), launched in 2013, and thereafter included in the broader Pacte de Responsabilité et de Solidarité (PRS). Our interest in analysing these fiscal reforms stems from the fact that they involve a reduction in labour taxes and capital income taxes at the same time. Their official aim is to boost real output growth, competitiveness and job creations. We will first provide a brief assessment of this package. Then, we will show that if the tax reductions contained in the CICE had been directed entirely towards capital income taxes, the whole package would have achieved its objectives more successfully.

Strictly speaking, the CICE constitutes a tax credit against capital income taxes, which is computed as a share of the gross payroll. It should therefore be simulated as a reduction in $\tau_{t}^{K}$. However, the classification of the CICE is not a clear-cut issue. Because of its design (as a share of total gross payroll), we could also interpret it as a cut of labour taxes. This is why many assessments of this package consider that it mainly corresponds to a reduction in $\tau_{t}^{W_{f}}$. Here, in our "baseline" scenario, we assume that the amount involved in the CICE corresponds to reductions in equal shares of both labour and capital income taxes. Conversely, in our "alternative" scenario, we simulated the counter-factual case, where the whole amount of the CICE would have been devoted to cuts in capital income taxes.

In addition, the PRS involves a clear reduction in the social security contributions of employers and in capital income taxes. Moreover, a "solidarity" component decreases personal income taxes paid by lowincome households. The cost of the whole CICE-PRS is expected to be financed by cuts in public spending, by a new environmental tax, and by increases in the VAT rates. Official announcements point to public expenditure cuts of EUR 50 billion for the 2014-17 period. Table 1 illustrates the composition of the PRS.

In order to focus the analysis only on the impact of cuts of labour and capital income taxes, our simulations (for both our "baseline" and "alternative" scenarios) do not include the aforementioned financing measures. ${ }^{9}$ Results are displayed in Fig. 6.

Fig. 6 shows that in the medium run, the CICE-PRS enhances real output, private investment and employment. With respect to the initial steady state, the three target variables show an improvement at the end of the period of about $2 \%, 9 \%$ and $0.7 \%$, respectively. This expansionary effect on real output is mainly driven by the contribution of the shock on capital taxes (green bars in figure Fig. 6). In the short run, however, results are more balanced. Indeed, the application of the CICE-PRS triggers an immediate decline in employment of nearly $0.4 \%$, which is absorbed in the following periods once activity recovers. Moreover, there is a mild decline in real output, due to the fall in private consumption.

The short-run fall in employment can be explained as follows. Cuts in $\tau_{t}^{K}$ and $\tau_{t}^{W_{f}}$ (represented by the green and yellow bars in Fig. 6) imply a substitution-effect regarding the other productive factor. In spite of the fact that the two initial shocks correspond to similar amounts in level, there is a whole substitution of capital for labour because of the difference in the tax base. In fact, since the tax base of $\tau_{t}^{K}$ is smaller than that for $\tau_{t}^{W_{f}}$, a similar shock in level translates into a higher decrease in the tax rate. In the long run, however, the reduction in $\tau_{t}^{K}$ fosters real output, which drives labour demand and employment up.

\footnotetext{
${ }^{9}$ The simulation results incorporating financing measures are available upon request.
} 
Foreign trade does not contribute to output growth in the long term although it has a positive impact in the first two years of implementation. The main driver behind this trend is the cut in capital income taxes. After an improvement in French competitiveness (embodied by the fall of inflation) in the first years, the strong increase in domestic demand (mainly through private investment) generates a trade deficit in the medium run.

The red lines of Fig. 7 illustrate the results of our "alternative" scenario, which would have been obtained if the total amount devoted to the CICE had been concentrated on reductions in $\tau_{t}^{K}$. For the sake of comparison, the results of our "baseline" scenario, for which the amount involved in the CICE is shared equally between reductions in $\tau_{t}^{W_{f}}$ and reductions in $\tau_{t}^{K}$, are also restated (blue lines).

Consistent with what we found in Section 4, the increase in private investment related to the "alternative" scenario would have been larger than that in the "baseline" scenario. Similarly, in the medium run, the rise in real output and in employment would also have been higher for the "alternative" case. Conversely, in the short run, the decline in employment would have been more pronounced with this scenario. Hence, a package more targeted towards cuts in capital income taxation would have improved private investment, real output and employment in the medium run to a larger extent, but at the expense of a deeper contraction of employment in the short run.

\section{Conclusion}

In this paper, we have shown (both for the short and the long run) that the basic ranking of tax multipliers of a RBC model is unchanged in a richer model of a euro area country that shares a common currency with the rest of the euro area: cuts in capital income tax have more powerful effects on real output than cuts in labour taxes for firms. Still, cuts in capital income taxes have detrimental effects on employment in the short and medium run. We have also stressed that the advantage of such tax reductions would be attenuated if the initial level of the tax rate was not as high as the French level, or if these tax reductions were expected to be only temporary. We finally assessed the impact of a recent fiscal package that was recently implemented in France, which combines both types of tax cuts, and argued that this package would have more substantially raised real output and employment in the medium run if the tax reductions had been more concentrated upon capital income.

For further research, the main issue would be to analyse how these results would be changed in a model that allows for incomplete insurance-markets. As such an assumption should matter greatly for consumption dynamics, it would be interesting to analyse its implications for the positive issues that we have looked at in this paper.

\section{Appendix A. Supplementary data}

Supplementary data related to this article can be found at https:// doi.org/10.1016/j.econmod.2017.12.019.

\section{References}

Berson, C., Devulder, A., Langot, F., Malgouyres, C., 2016. Maquette France-Zone Euro, Évaluation de politiques de baisse du coût du travail en France. Mimeo.

Bussière, M., Ferrara, L., Juillard, M., Siena, D., 2017. Can Fiscal Budget-neutral Reforms Stimulate Growth? Model-based Results. Working papers 625. Banque de France.

Cahuc, P., Carcillo, S., 2014. Alléger le coû t du travail pour augmenter l'emploi. Etudes de l'Institut Montaigne.

Castelletti, B., Clerc, P., Lemoine, M., 2017. Should Euro Area Countries Cut Taxes on Labour or Capital in Order to Boost Their Growth? Working Paper 634. Banque de France.

Chamley, C., 1986. Optimal taxation of capital income in general equilibrium with infinite lives. Econometrica 54 (3).

Coenen, G., McAdam, P., Straub, R., 2008. Tax reform and labor-market performance in the Euro Area: a simulation-based analysis using the new area-wide model. J. Econ. Dynam. Contr. 32 (8).

European Commission, 2013. Tax reforms in EU member states 2013. Eur. Econ. 52013.

Farhi, E., Gopinath, G., Itskhoki, O., 2014. Fiscal devaluations. Rev. Econ. Stud. 81 (2).

Fève, P., Sahuc, J.-G., Matheron, J., 2010. La TVA sociale : bonne ou mauvaise idée? Écon. Prévision 193 (2).

Gomes, S., Jacquinot, P., Pisani, M., 2012. The EAGLE: a model for policy analysis of macroeconomic interdependence in the Euro Area. Econ. Modell. 29 (5).

Gomes, S., Jacquinot, P., Pisani, M., 2016. Fiscal devaluation in the euro area: a model-based analysis. Econ. Modell. 52 (Part A).

Heathcote, J., 2005. Fiscal policy with heterogeneous agents and incomplete markets. Rev. Econ. Stud. 72 (1).

IMF, October 2014. Back to work: how fiscal policy can help. Fiscal Monit.

Judd, K.L., 1985. Redistributive taxation in a simple perfect foresight model. J. Publ. Econ. 28 (1)

Langot, F., Patureau, L., Sopraseuth, T., 2012. Optimal Fiscal Devaluation. CEPREMAP Working Papers, No.1202.

Lipinska, A., von Thadden, L., 2009. Monetary and Fiscal Policy Aspects of Indirect Tax Changes in a Monetary Union. ECB Working Paper Series, No.1097.

Smets, F., Wouters, R., 2003. An estimated dynamic stochastic general equilibrium model of the Euro Area. J. Eur. Econ. Assoc. 1 (5).

Further reading

Artus, P., Bozio, A., Garcia-Penalosa, C., 2013. Fiscalit é des Revenus du Capital. Notes du conseil d'analyse économique, No. 9.

Baxter, M., King, R., 1993. Fiscal policy in general equilibrium. Am. Econ. Rev. 83 (3).

Christoffel, K., Coenen, G., Warne, A., 2008. The New Area-wide Model of the Euro Area: a Micro-founded Open-economy Model for Forecasting and Policy Analysis. Working Paper Series 0944. European Central Bank.

Clancy, D., Jacquinot, P., Lozej, M., 2014. The Effects of Government Spending in a Small Open Economy within Monetary Union. Working Paper Series No.1727. European Central Bank.

Kilponen, J., Pisani, M., Schmidt, S., Corbo, V., Hledik, T., Hollmayr, J., Hurtado, S. Júlio, P., Kulikov, D., Lemoine, M., Lozej, M., Lun, 2015. Comparing Fiscal Multipliers across Models and Countries in Europe. Working Paper Series 1760European Central Bank.

Leeper, E., Walker, T., Yang, S., 2010. Government investment and fiscal stimulus. J. Monetary Econ. 57 (8).

Straub, R., Tchakarov, I., 2007. Assessing the Impact of a Change in the Composition of Public Spending: a DSGE Approach. Working Paper Series 0795, European Central Bank.

World Economic Outlook, October 2014. Is it Time for an Infrastructure Push ? the Macroeconomic Effects of Public Investment. Chapter 3. International Monetary Fund. 